Supplementary information for the manuscript:

\title{
Sulindac Sulfide Induces the Formation of Large Oligomeric Aggregates of the Alzheimer's Disease Amyloid- $\beta$ Peptide Which Exhibit Reduced Neurotoxicity
}

\section{Authors:}

Elke Prade ${ }^{1}$, Dr. Christian Barucker ${ }^{2}$, Dr. Riddhiman Sarkar ${ }^{1}$, Dr. Gerhard Althoff-Ospelt ${ }^{3}$, Dr. Juan Miguel Lopez del Amo ${ }^{4}$, Shireen Hossain², Yifei Zhong ${ }^{2}$, Prof. Dr. Gerd Multhaup ${ }^{2}$, Prof. Dr. Bernd Reif ${ }^{* 1,5}$

\section{Affiliations:}

${ }^{1}$ Munich Center for Integrated Protein Science (CIPS-M) at Department Chemie, Technische Universität München (TUM), Lichtenbergstr. 4, 85747 Garching, Germany.

${ }^{2}$ Department of Pharmacology \& Therapeutics, McGill University, 3655 Promenade SirWilliam-Osler, Montreal QC, H3G 1Y6, Canada.

${ }^{3}$ Bruker BioSpin, Silberstreifen 4, 76287 Rheinstetten, Germany.

${ }^{4}$ Current address: CIC Energigune, Albert Einstein 48, 01510 Miñano, (Álava), Spain.

${ }^{5}$ Helmholtz-Zentrum München (HMGU), Deutsches Forschungszentrum für Gesundheit und Umwelt, Ingolstädter Landtstr. 1, 85764 Neuherberg, Germany.

*Email: reif@tum.de 


\section{Table of Contents}

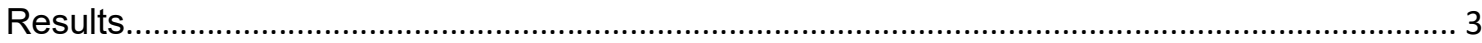

Supplementary Figure 1: Solution-state NMR of $A \beta$ and NSAIDs....................................... 3

Supplementary Figure 2: Analysis of solution-state NMR of $A \beta$ and NSAIDs. ...................... 4

Supplementary Figure 3: Solution-state NMR studies of $A \beta$ sidechains and NSAIDs. ......... 5

Supplementary Figure 4: Solid-state NMR spectra of NSAID induced A $\beta$ aggregates......... 6

Supplementary Figure $5:{ }^{13} \mathrm{C}-{ }^{19} \mathrm{~F}$ TEDOR spectra of NSAID induced $A \beta$ aggregates........... 7

Supplementary Figure 6: Solid-state NMR pulse sequences. .................................................. 8

Supplementary Figure 7: Comparison of ${ }^{13} \mathrm{C}-{ }^{19} \mathrm{~F}$ dipolar contacts between sulindac sulfide

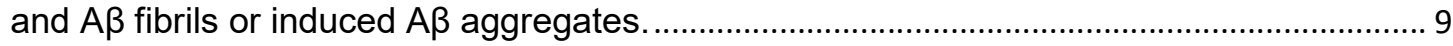

Supplementary Table 1: Chemical shifts assigned for $A \beta$ aggregates induced by a 10 -fold

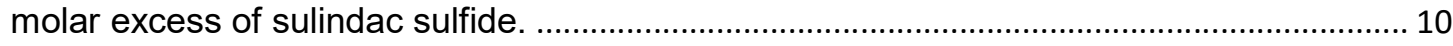

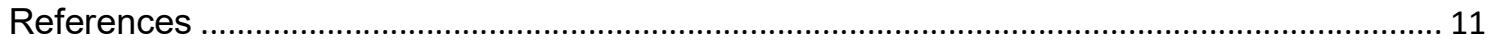




\section{Results}

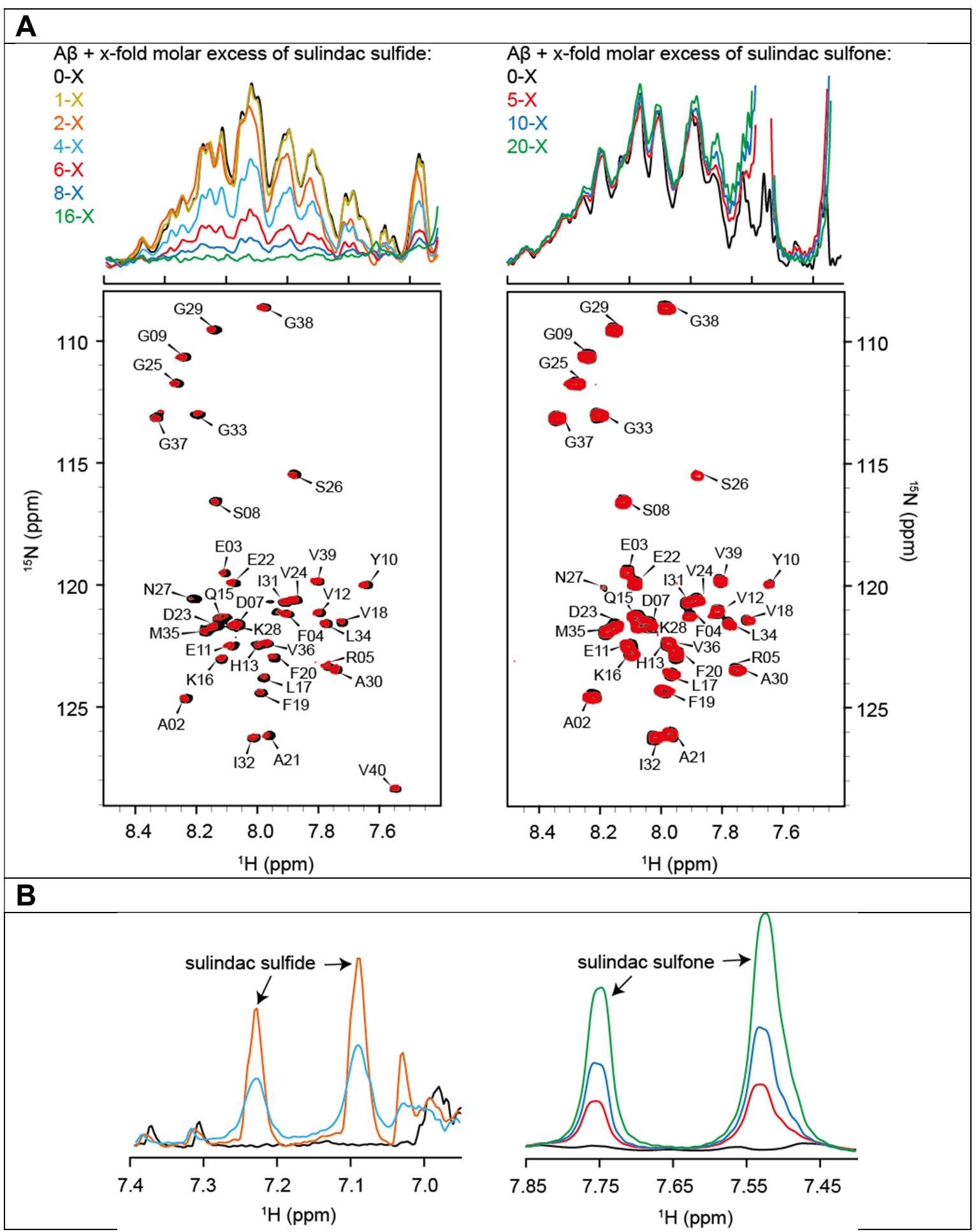

Supplementary Figure 1: Solution-state NMR of $A \boldsymbol{\beta}$ and NSAIDs. (A) ${ }^{1} \mathrm{H}-1 \mathrm{D}$ NMR spectra of monomeric $A \beta$ in the presence of increasing concentrations of sulindac sulfide (left) and sulindac sulfone (right), as well as ${ }^{1} \mathrm{H}-{ }^{15} \mathrm{~N}$ HSQC of $A \beta$ in the absence (black) and presence (red) of a 6-fold molar excess of sulindac sulfide (left) and 
sulindac sulfone (right). Loss of signal intensities are observed with increasing concentrations of the NSAID, indicating aggregation of $A \beta$. (B) ${ }^{1} \mathrm{H}-1 \mathrm{D}$ NMR spectra of characteristic signals of sulindac sulfide (left) and sulindac sulfone (right) in the presence of a $50 \mu \mathrm{M}$ monomeric $A \beta$ solution. Signal intensities are attenuated and broadened at a 4-fold molar excess of sulindac sulfide (blue) compared to lower concentrations (orange), whereas NMR signals of sulindac sulfone show an increase in peak intensity corresponding to the increase in NSAID concentration.

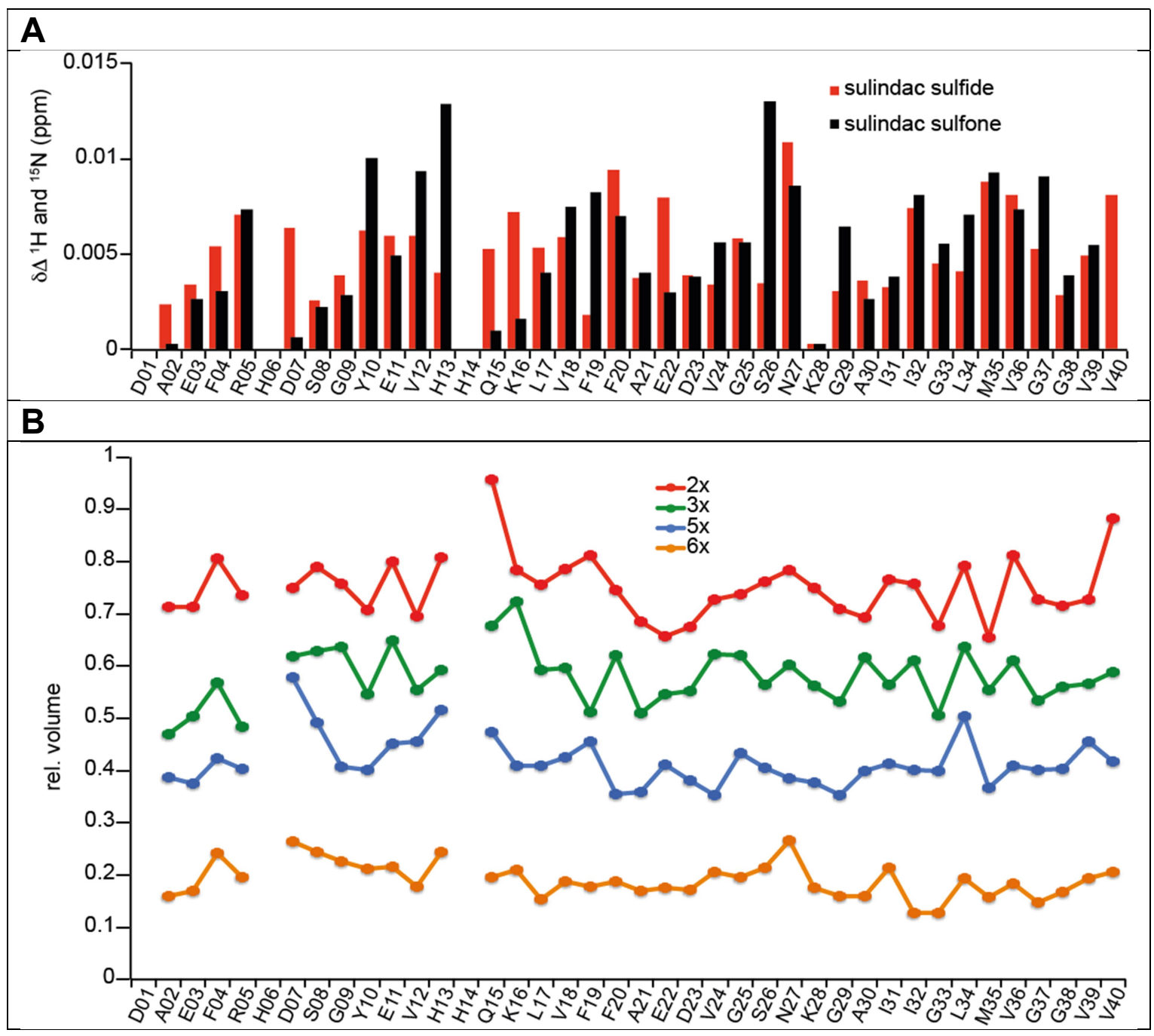

Supplementary Figure 2: Analysis of solution-state NMR of $A \boldsymbol{\beta}$ and NSAIDs. (A) CSPs $\Delta \delta$ (ppm) observed for $A \beta$ in the presence of 5-fold molar excesses of sulindac sulindac sulfide (red) and sulindac sulfone (black) compared to monomeric $A \beta$. (B) Relative volumes of $A \beta$ incubated in the presence of increasing amounts of sulindac sulfide extracted from ${ }^{1} \mathrm{H}-{ }^{15} \mathrm{~N}$ HSQC signals. 


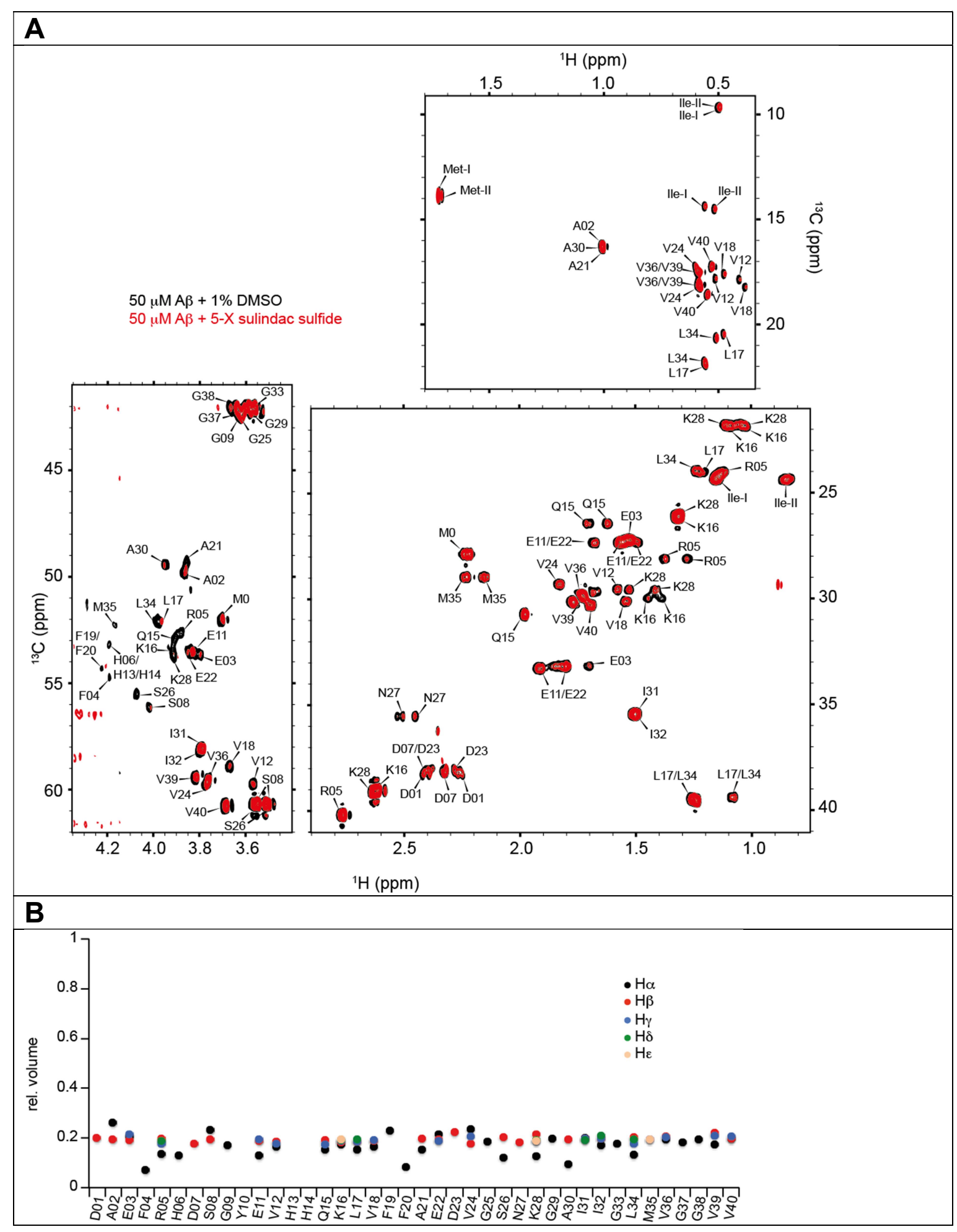

Supplementary Figure 3: Solution-state NMR studies of $A \beta$ sidechains and NSAIDs. $(A){ }^{1} H_{-}{ }^{13} \mathrm{C} H S Q$ of $A \beta$ in the presence of a 5 -fold molar excess of sulindac sulfide (red) and $1 \% \mathrm{DMSO}$ as a control (black). (B) relative volumes of ${ }^{1} \mathrm{H}^{13} \mathrm{C} A \beta$ cross-peaks in the presence of a 5 -fold molar excess of sulindac sulfide. 


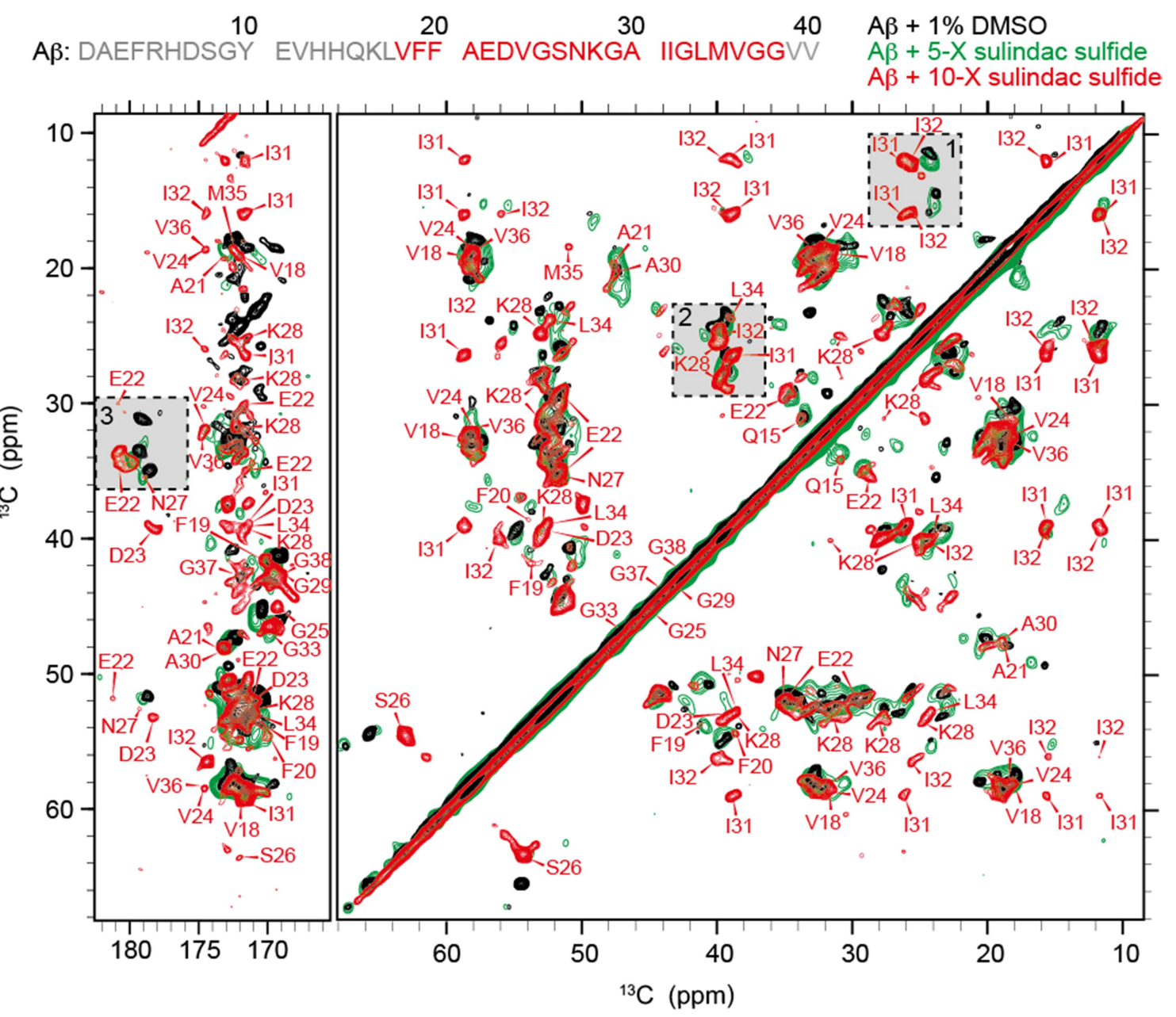

Supplementary Figure 4: Solid-state NMR spectra of NSAID induced $A \beta$ aggregates. ${ }^{13} \mathrm{C}-{ }^{13} \mathrm{C}$ PDSD correlation spectrum of $A \beta$ aggregated in the presence of a 5-fold (green) and 10-fold (red) molar excess of sulindac sulfide and 1\% DMSO after 1 day, as well as $A \beta$ in the presence of only $1 \%$ DMSO (black) as a control. NCACX and NCOCX experiments allowed sequential assignment of chemical shifts of individual resonances for residues E22-G38 for $A \beta$ incubated in the presence of a 10-fold molar excess of sulindac sulfide (red). Squares indicated 1-3 are magnified in Fig. 3A. 


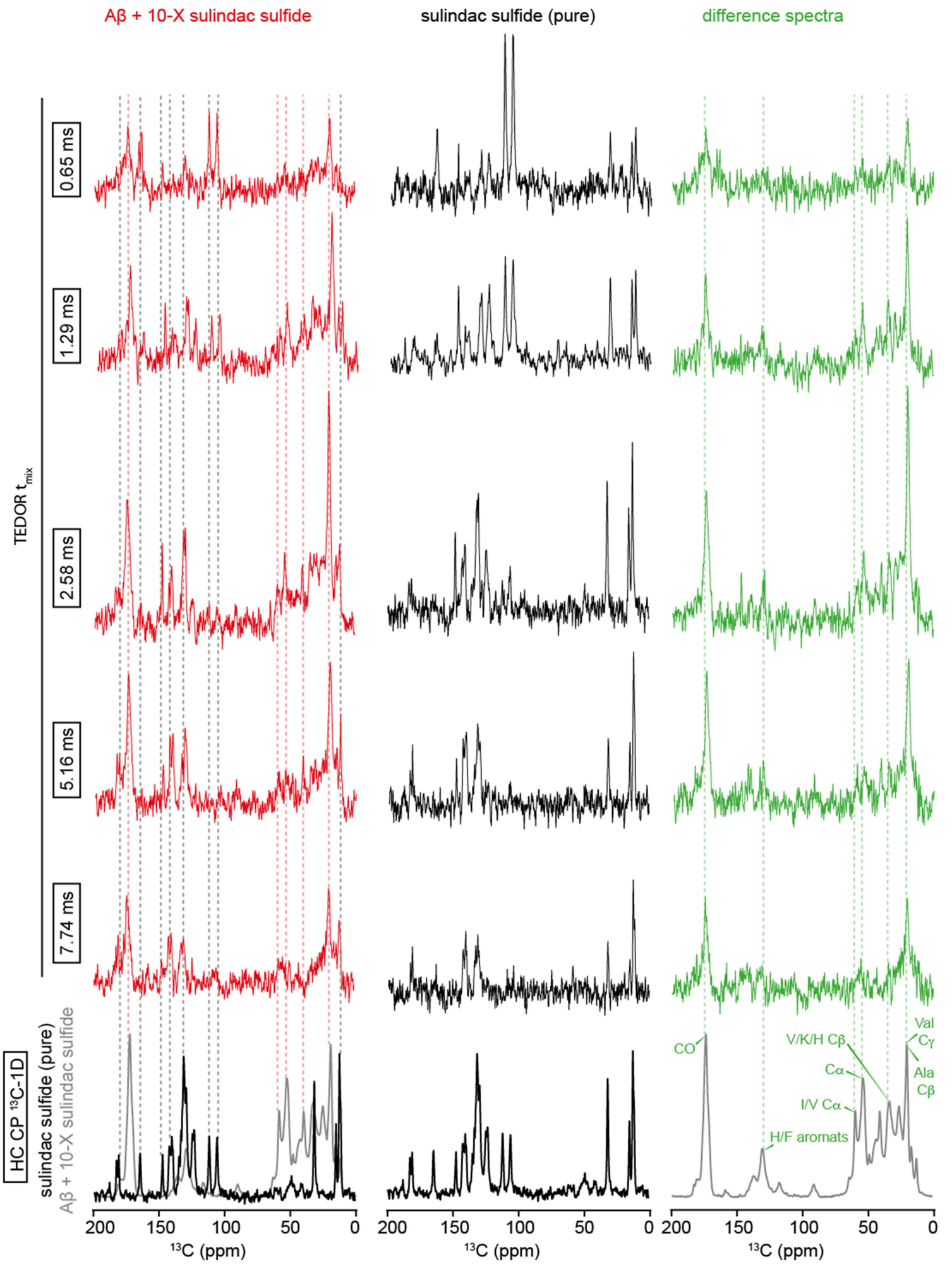

Supplementary Figure $5:{ }^{13} \mathrm{C}-{ }^{19} \mathrm{~F}$ TEDOR spectra of NSAID induced $A \beta$ aggregates. ${ }^{13} \mathrm{C}-{ }^{19} \mathrm{~F}$ TEDOR spectra to detect dipolar contacts between ${ }^{13} \mathrm{C}$ and ${ }^{19} \mathrm{~F}$ atoms in $\mathrm{A} \beta$ aggregates induced by sulindac sulfide (red), and for pure sulindac sulfide (black), respectively. The experiments were run with mixing times of $0.65,1.29,2.58,5.16$ and $7.74 \mathrm{~ms}$. The sulindac sulfide spectra were subtracted from the spectrum obtained for $A \beta$ aggregates with a 
factor 0.5 to yield the difference spectra (green). In the lowest row, the $\mathrm{HC} \mathrm{CP}{ }^{13} \mathrm{C}-1 \mathrm{D}$ experiments which show all ${ }^{13} \mathrm{C}$ atoms in $\mathrm{A} \beta$ aggregates (gray) and pure sulindac sulfide (black) is represented. Vertical connecting lines are drawn to the full ${ }^{13} \mathrm{C}$ spectra to guide the eye.
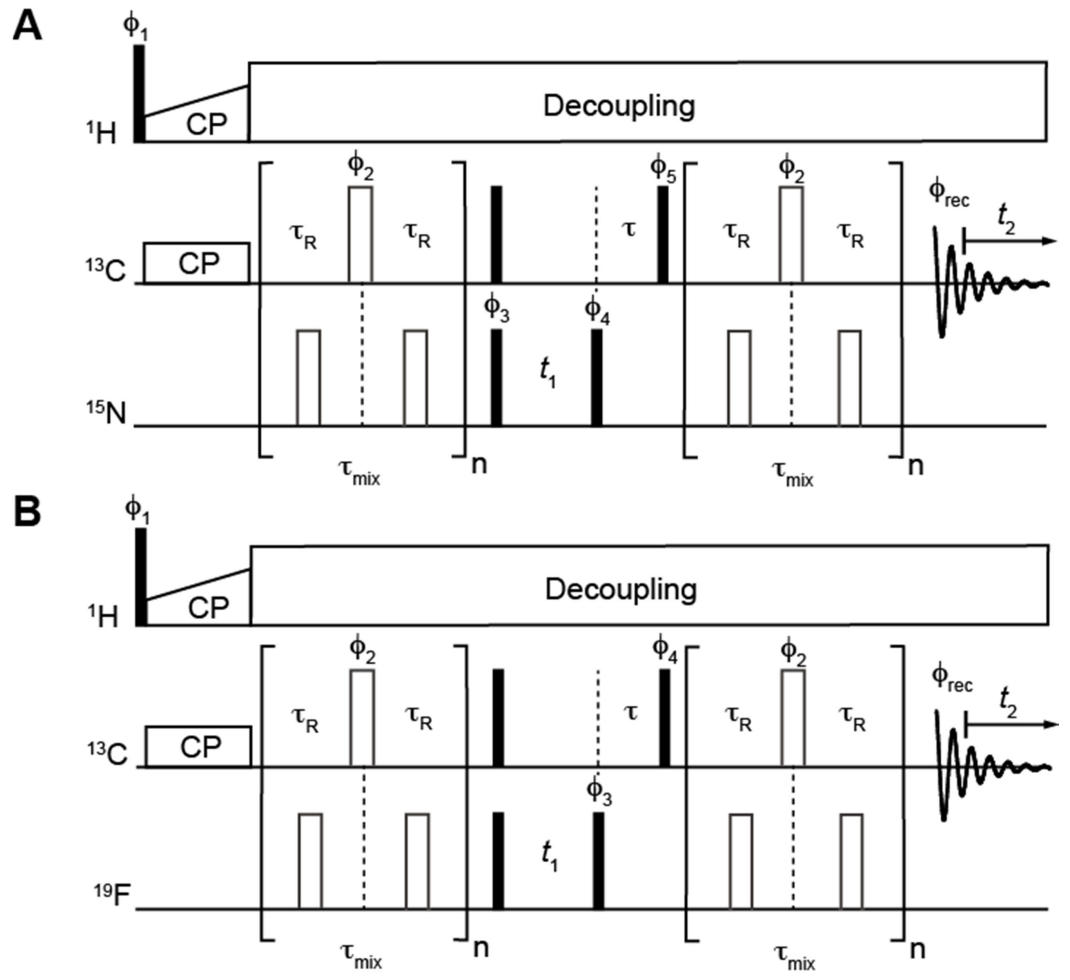

Supplementary Figure 6: Solid-state NMR pulse sequences. (A) ${ }^{13} \mathrm{C}-{ }^{15} \mathrm{~N}$ TEDOR pulse sequence used to detect the D23C $\gamma-\mathrm{K} 28 \mathrm{~N} \zeta$ salt bridge and $(\mathrm{B}){ }^{13} \mathrm{C}-{ }^{19} \mathrm{~F}$ TEDOR pulse sequence used to detect ${ }^{13} \mathrm{C}$ atoms near the ${ }^{19} \mathrm{~F}$ - atom of sulindac sulfide. The pulse sequences are based on the 3D TEDOR experiments described by Jaroniec et al. ${ }^{1}$ Black rectangles represent $\pi / 2$-pulses and white rectangles represent $\pi$-pulses. Both experiment start with a ${ }^{1} \mathrm{H}-{ }^{13} \mathrm{C}$ CP transfer. The TEDOR sequences consists of two REDOR periods, which allow to transfer magnetization from ${ }^{13} \mathrm{C}$ to $\mathrm{S}$ spins, followed by an evolution period $\mathrm{t}_{1}$. The experiment to detect the salt bridge was recorded in 2D-mode; the experiment to identify ${ }^{19} \mathrm{~F}$ nuclei near ${ }^{13} \mathrm{C}$ atoms was recorded in $1 \mathrm{D}$-mode. The following phase-cycles were used: $(A) \phi_{1}=y,-y ; \phi_{2}=y ; \phi_{3}=x, x,-x,-x ; \quad \phi_{4}=-x ; \phi_{5}=y, y, y, y,-y,-y,-y,-y$; $\phi_{\text {rec }}=x,-x,-x, x,-x, x, x,-x$; the REDOR m-pulses on ${ }^{15} N$ are phase-cycled employing the $x y-16$ scheme. ${ }^{2}(B)$ $\phi_{1}=y,-y ; \phi_{2}=y ; \phi_{3}=x, x,-x-x ; \phi_{4}=(x)^{\star} 4,(y)^{*} 4,(-x)^{\star} 4(-y)^{*} 4 ; \phi_{\text {rec }}=-x, x, x,-x, y,-y,-y, y, x,-x,-x, x,-y, y, y,-y$. The REDOR $\pi$-pulses on the ${ }^{19}$ F-spins are phase-cycled eomplyoing the $x y-16$ scheme. The phases for all other pulses were set to $\mathrm{x}$. 


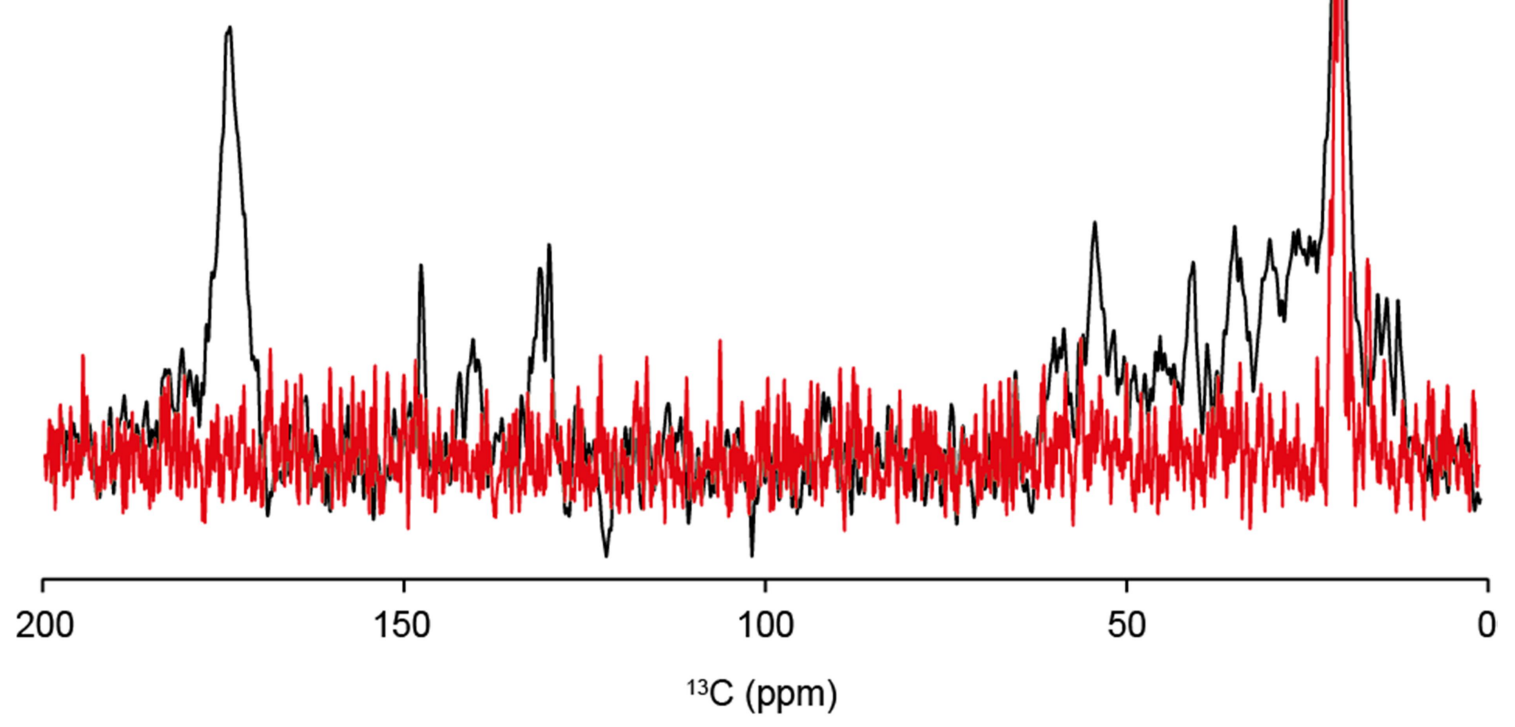

Supplementary Figure 7: Comparison of ${ }^{13} \mathrm{C}-{ }^{19} \mathrm{~F}$ dipolar contacts between sulindac sulfide and $A \beta$ fibrils or induced $A \beta$ aggregates. Black: ${ }^{13} \mathrm{C}-{ }^{19} \mathrm{~F}$ TEDOR spectrum for a sample in which sulindac sulfide was titrated to monomeric $A \beta$ using a 10-fold molar excess of sulindac sulfide. The TEDOR mixing time was set to of $2.58 \mathrm{~ms}$. Red: ${ }^{13} \mathrm{C}-{ }^{19} \mathrm{~F}$ REDOR spectrum for a sample in which a 5 -fold molar excess of sulindac sulfide was titrated to preformed $A \beta$ fibrils. ${ }^{3}$ In this experiment, the mixing time was set to $4.4 \mathrm{~ms}$. 


\begin{tabular}{|c|c|c|c|c|c|c|c|c|}
\hline aa & $\mathbf{N}$ & $\mathrm{CO}$ & $\mathrm{Ca}$ & $C \beta$ & Cy & Cठ & $\mathrm{C} \varepsilon$ & Nל \\
\hline V18 & - & 171.83 & 58.27 & 32.25 & 18.73 & - & - & \\
\hline F19 & 131.00 & 170.35 & 53.33 & 41.27 & & 128.84 & & \\
\hline F20 & 128.77 & 169.74 & 54.15 & 38.62 & & 129.96 & 128.25 & \\
\hline A21 & 127.50 & 173.07 & 47.75 & 19.12 & - & - & - & \\
\hline E22 & 126.69 & 171.44 & 51.49 & 29.63 & 34.51 & 181.30 & - & \\
\hline D23 & 121.89 & 171.38 & 52.84 & 39.06 & 178.56 & - & - & \\
\hline V24 & 120.97 & 174.46 & 57.97 & 31.62 & 18.29 & - & - & \\
\hline G25 & 115.63 & 169.25 & 44.75 & - & - & - & - & \\
\hline S26 & 108.56 & 171.97 & 54.47 & 63.10 & - & - & - & \\
\hline N27 & 125.26 & 170.33 & 52.03 & 35.14 & 179.51 & - & - & \\
\hline K28 & 131.22 & 171.59 & 52.85 & 31.18 & 24.94 & 27.84 & 39.32 & 36.8 \\
\hline G29 & 115.15 & 169.36 & 42.21 & - & - & - & - & \\
\hline A30 & 130.05 & 173.15 & 47.60 & 19.82 & - & - & & \\
\hline I31 & 127.18 & 171.42 & 58.40 & 38.77 & $\begin{array}{l}15.43 \\
26.08\end{array}$ & 11.76 & & - \\
\hline 132 & 129.06 & 174.46 & 55.99 & 39.61 & $\begin{array}{l}15.52 \\
25.34\end{array}$ & 11.74 & & - \\
\hline G33 & 121.73 & 169.49 & 45.97 & - & - & - & & \\
\hline L34 & 120.88 & 171.84 & 50.72 & 43.91 & 25.15 & $\begin{array}{l}23.05 \\
22.46\end{array}$ & & - \\
\hline M35 & 122.16 & 172.32 & 50.79 & - & 31.26 & - & 18.47 & \\
\hline V36 & - & 174.88 & 57.66 & 32.13 & 18.16 & - & - & \\
\hline G37 & 111.25 & 171.63 & 42.28 & - & - & - & - & \\
\hline G38 & 112.67 & 169.52 & 41.94 & - & - & - & - & \\
\hline
\end{tabular}

Supplementary Table 1: Chemical shifts assigned for $A \beta$ aggregates induced by a 10 -fold molar excess of sulindac sulfide. 


\section{References}

[1] Jaroniec, C. P., Filip, C., and Griffin, R. G. (2002) 3D TEDOR NMR experiments for the simultaneous measurement of multiple carbon-nitrogen distances in uniformly $(13) \mathrm{C},(15) \mathrm{N}$-labeled solids, J. Am. Chem. Soc. 124, 10728-10742.

[2] Gullion, T., Baker, D. B., and Conradi, M. S. (1990) New, compensated Carr-Purcell sequences, J. Magn. Reson. 89, 479-484.

[3] Prade, E., Bittner, H. J., Sarkar, R., Lopez Del Amo, J. M., Althoff-Ospelt, G., Multhaup, G., Hildebrand, P. W., and Reif, B. (2015) Structural Mechanism of the Interaction of Alzheimer Disease Abeta Fibrils with the Non-steroidal Anti-inflammatory Drug (NSAID) Sulindac Sulfide, J. Biol. Chem. 290, 28737-28745. 